\title{
Experimental Set-Up for Evaluation of Electro-Magnetic Characteristics of High-Tc Superconductors Cooled by Liquid Hydrogen
}

\section{AUTHOR(S):}

Shirai, Yasuyuki; Hikawa, Kyosuke; Shiotsu, Masahiro; Tatsumoto, Hideki; Hata, Koichi; Kobayashi, Hiroaki; Nonaka, Satoshi; Naruo, Yoshihiro; Inatani, Yoshifumi

\section{CITATION:}

Shirai, Yasuyuki ... [et al]. Experimental Set-Up for Evaluation of Electro-Magnetic Characteristics of High-Tc Superconductors Cooled by Liquid Hydrogen. IEEE Transactions on Applied Superconductivity 2013, 23(3): 9500404.

\section{ISSUE DATE:}

2013-06

\section{URL:}

http://hdl.handle.net/2433/171244

\section{RIGHT:}

(c) 2013 IEEE. Personal use of this material is permitted. Permission from IEEE must be obtained for all other uses, in any current or future media, including reprinting/republishing this material for advertising or promotional purposes,

creating new collective works, for resale or redistribution to servers or lists, or reuse of any copyrighted component of this work in other works.; This is not the published version. Please cite only the published version.; この論文は出版社版 でありません。引用の際には出版社版をご確認ご利用ください。 


\author{
Yasuyuki Shirai, Member IEEE, Kyosuke Hikawa, Masahiro Shiotsu, Hideki Tatsumoto, Koichi Hata, \\ Hiroaki Kobayashi, Satoshi Nonaka, Yoshihiro Naruo and Yoshifumi Inatani
}

\begin{abstract}
Liquid hydrogen $\left(\mathrm{LH}_{2}\right)$ has excellent properties as a coolant, such as large latent heat, low viscosity coefficient and so on. Not only $\mathrm{MgB}_{2}$ but also other high-Tc superconductors are expected to have excellent properties with being cooled by $\mathrm{LH}_{2}$. It is necessary for a stability design of a high-Tc superconductor cooled by $\mathrm{LH}_{2}$ to make an electro-magnetic characteristic clear. However, due to the handling difficulties of $\mathrm{LH}_{2}$, there are only few papers on the properties of $\mathrm{LH}_{2}$ cooled superconductors, especially under the external magnetic field. In this paper, an experimental set-up, which was designed and fabricated for evaluation of electro-magnetic characteristics of high-Tc superconductors cooled by $\mathbf{L H}_{2}$, is described. The $\mathbf{L H}_{2}$ cryostat of $309 \mathrm{~mm}$ inner diameter was set co-axially with vacuum layer in the LHe cryostat in which the LHe cooled superconducting magnet for external magnetic field (up to $7 \mathrm{~T}$ ) was set. The $\mathbf{L H}_{2}$ cryostat has three power leads for feeding up to $500 \mathrm{~A}$ to the test high-Tc superconductors.
\end{abstract}

Index Terms - liquid hydrogen, heat transfer, magnetic field, high-Tc superconductor

\section{INTRODUCTION}

$\mathrm{L}$ IQUID hydrogen $\left(\mathrm{LH}_{2}\right)$ has excellent properties as a

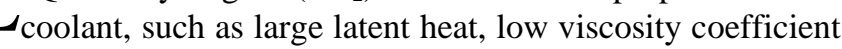
and so on [1]-[3]. Generally, the high-Tc superconductors, such as YBCO and BSCCO are cooled by liquid nitrogen $(77 \mathrm{~K})$. However, it is considered that the excellent electromagnetic properties of such materials are achieved with temperature of $20-40 \mathrm{~K}$. There are many application studies with this temperature region using cryo-coolers. The characteristics of Jc-B (critical current density and critical magnetic flux density) of high-Tc superconductors cooled by $\mathrm{LH}_{2}$ are not so degraded from those with $\mathrm{LHe}$ temperature (4.2 $\mathrm{K}$ ), but the heat capacity of the materials in $\mathrm{LH}_{2}$ becomes much larger than that in $\mathrm{LHe}$. While $\mathrm{MgB}_{2}$ superconductor has been developing years by years, $\mathrm{LH}_{2}$ is expected to be the coolant for that material whose critical temperature is $39 \mathrm{~K}$.

Manuscript received 9 October 2012. This research was supported in part by JST-ALCA, Japan.

Y. Shirai, K. Hikawa, M. Shiotsu are with Dept. of Energy Science and Technology, Kyoto Univ., Yoshida-Honmachi, Sakyo-ku, Kyoto, 606-8501 Japan (Tel.:+81-75-753-3328 e-mail: shirai@ pe.energy.kyoto-u.ac.jp).

H. Tatsumoto is with J-PARC Center, Japan Atomic Energy Agency, Tokai, Ibaraki, Japan.

K. Hata is with Institute of Advanced Energy, Kyoto Univ., Kyoto, Japan.

H. Kobayashi, S. Nonaka, Y. Naruo, Y. Inatani are with Institute of Space and Astronautical Science, JAXA, Kanagawa, Japan.
However there are many difficulties to handle gas and liquid hydrogen because of its explosive nature. For the first step, we have developed a thermal-hydraulics experimental system for liquid hydrogen in order to investigate heat transfer characteristics for wide ranges of subcoolings, pressures up to supercritical and flow velocities in forced flow cooling. Basic data on immersion cooling and forced flow cooling of liquid hydrogen are especially required for the design of applied superconductivity apparatus. Details on the experimental system and preliminary operation results have been already reported [4]-[6].

In addition to the cooling properties of liquid hydrogen, it is necessary to evaluate electro-magnetic properties of superconductors cooled by liquid hydrogen. Cooling stability in steady state and transient state of superconductors and their coils cooled by $\mathrm{LH}_{2}$ in a certain magnetic field is important issue for design $\mathrm{LH}_{2}$ cooled superconducting power apparatus. In this paper, an additional experimental set-up, which was designed and fabricated for the above purpose, and experimental results of cooling test, basic operation test are described. Remote control systems and interlock systems were also designed to carry out the experiment safely.

\section{CRYOSTAT}

\section{A. Design Criteria}

Purposes of the experimental setup are for evaluation of electro-magnetic properties of high-Tc superconductors cooled by $\mathrm{LH}_{2}$. The set-up provides circumstances that not only short sample of a test superconductor but a small superconducting coil $\left(\sim 300 \mathrm{~mm}\right.$ diameter) cooled by $\mathrm{LH}_{2}$ can be tested with excitation of various current patterns $(\sim 500 \mathrm{~A})$ in a certain magnetic field $(\sim 7 \mathrm{~T})$. Test conditions are the pressure of $\sim 2.0$ $\mathrm{MPa}$ (up to supercritical critical pressure of $\mathrm{LH}_{2}$ whose critical pressure is $1.293 \mathrm{MPa}$ ) and the temperature of $14 \mathrm{~K} \sim 32 \mathrm{~K}$ (subcooled condition under several pressures).

\section{B. General Configuration}

Experimental setup was designed and made as shown in Fig.1 (photo view) and Fig.2 (cross-sectional view). Main components of the setup are a LHe cryostat equipped with a superconducting magnet, and a main $\mathrm{LH}_{2}$ cryostat inside the LHe cryostat with concentric arrangement, thermally insulated by vacuum layer. Major specification of the test facility is listed in Table I. 
TABLE I

SPECIFICATION OF CRYOSTAT AND MAGNET

\begin{tabular}{cc}
\hline \hline \multicolumn{2}{c}{ Liquid Hydrogen Cryostat } \\
\hline Inner diameter & $309.5 \mathrm{~mm}$ \\
Height (bottom to top flange) & $2218 \mathrm{~mm}$ \\
Volumetric capacity for $\mathrm{LH}_{2}$ & $61 \mathrm{~L} \mathrm{max}$ \\
\hline \hline \multicolumn{2}{c}{ Liquid Helium Cryostat } \\
\hline Inner diameter & $350 \mathrm{~mm}$ \\
Outer diameter & $630 \mathrm{~mm}$ \\
Height (bottom to top flange) & $1625 \mathrm{~mm}$ \\
Volumetric capacity for LHe & $175 \mathrm{~L} \mathrm{max}$ \\
\hline \hline Superconducting Magnet \\
\hline Material & $\mathrm{NbTi}$ \\
Inductance & $112.36 \mathrm{H}$ \\
Rated current & $175 \mathrm{~A}$ \\
Max. magnetic field (center) & $7 \mathrm{~T}$ \\
\hline
\end{tabular}

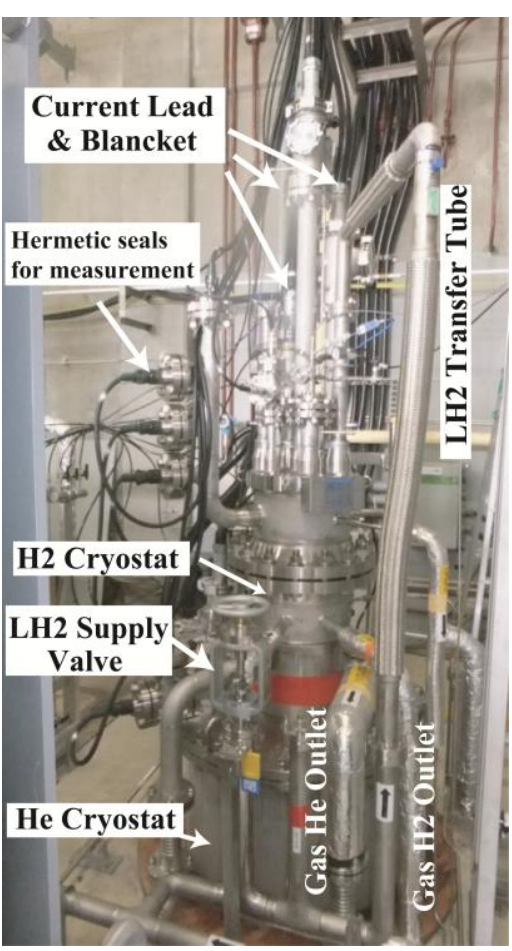

Fig. 1. Photo view of test facility (manufactured by JeccTorisha, Japan). The cryostats were set about $1 \mathrm{~m}$ under the ground level.

\section{Liquid Hydrogen Cryostat}

The $\mathrm{LH}_{2}$ cryostat is a vacuum insulated cylindrical stainless steel vessel whose inner diameter is $309 \mathrm{~mm}$ and height is $2218 \mathrm{~mm}$. Its inner filling capacity is $61 \mathrm{~L}$. The cryostat is designed for pressures up to $2.0 \mathrm{MPa}$ available for tests with supercritical condition.

Test temperature of $\mathrm{LH}_{2}$ can be set from $14 \mathrm{~K}$ to $32 \mathrm{~K}$ according to the pressures. Sheath heater $(\sim 500 \mathrm{~W})$ is set undermost area of the $\mathrm{LH}_{2}$ cryostat. It is used for setting subcooling of the $\mathrm{LH}_{2}$ under a certain pressures. A LHe forced flow line was set in the $\mathrm{LH}_{2}$ area for heat exchange with $\mathrm{LH}_{2}$ to obtain subcooling below $20 \mathrm{~K}$. A gas hydrogen feeding port was set at the bottom of the cryostat to scramble up $\mathrm{LH}_{2}$ for avoiding thermal stratification.

Five temperature sensors (Cernox) were set at $\mathrm{LH}_{2}$ level of 50, 40, 20, 16 and $13 \mathrm{~L}$. The sensors are used for monitoring not only the temperature but also the $\mathrm{LH}_{2}$ level. $\mathrm{A} \mathrm{LH}_{2}$ level sensor using $\mathrm{MgB}_{2}$ wire was also equipped

The $\mathrm{LH}_{2}$ cryostat has three power lead terminals for test sample (superconductors) excitation. The power leads (up to $500 \mathrm{~A}$ ) are covered with blankets pressurized by nitrogen gas kept slightly higher $(5 \mathrm{kPa})$ than the atmospheric pressure for explosion-protection.

Total conductive heat was estimated to be $14.7 \mathrm{~W}$ without feeding current to test samples.

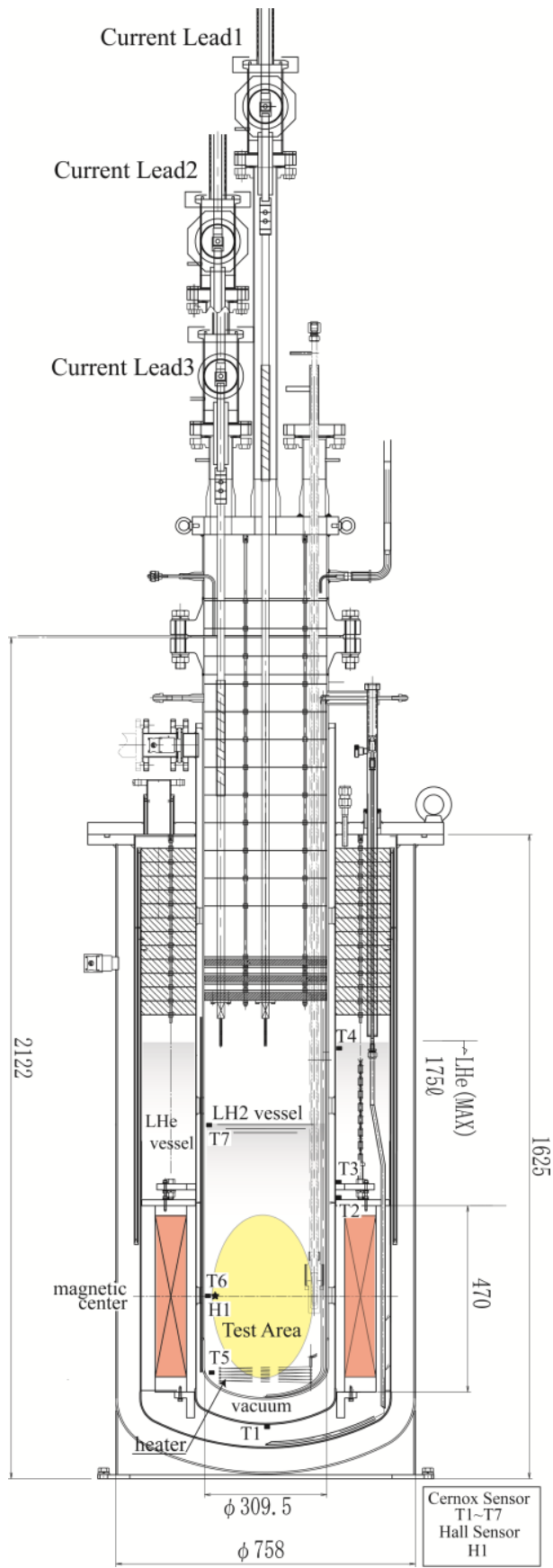

Fig. 2. Cross-sectional view of cryostats for electro-magnetic property tests of liquid hydrogen cooled superconductors. 


\section{Superconducting Magnet}

The superconducting magnet is of $406.4 \mathrm{~mm}$ height, 400.1 $\mathrm{mm}$ inner diameter and $558.8 \mathrm{~mm}$ outer diameter. Inductance is $112.36 \mathrm{H}$ and rated current is $175 \mathrm{~A}(7 \mathrm{~T})$. The $\mathrm{LH}_{2}$ cryostat is equipped though the bore area of the magnet. Maximum current sweep rate is $0.09 \mathrm{~A} / \mathrm{s}$. It takes about one hour to excite the magnet up to $7 \mathrm{~T}$ of test area field.

\section{E. Liquid Helium Cryostat}

There are three major problems in LHe Cryostat design.

First, LHe cryostat has superconducting magnet and two 200 A class power leads for magnet excitation which are covered with blankets filled with pressurized nitrogen gas for explosion-protection especially at the quench of the magnet.

Second, even if the quench occurs at the $7 \mathrm{~T}$ (175 A) operation, the stored energy of $1.71 \mathrm{MJ}$ is dissipated in shunt diodes connected parallel to the magnet and is used to evaporate the liquid helium and to raise the material $(154 \mathrm{~kg})$ temperature. Temperature rise of the magnet wire at the quench was roughly estimated to be less than $105 \mathrm{~K}$.

The blow-off rate and the pressure are estimated $400 \mathrm{~g} / \mathrm{s}$ and $0.04 \mathrm{MPa}$, respectively using blow-off valve whose nominal diameter is $50 \mathrm{~A}$.

Third, to keep the test time (including magnetization and demagnetization) more than 5 hours, the conductive heat through $\mathrm{LH}_{2}$ and LHe cryostats walls and the current leads made of copper should be reduced less than $18 \mathrm{~W}$, which is calculated from the capacity $100 \mathrm{~L}$ of LHe overhead the magnet. Total conductive heat was designed $14.5 \mathrm{~W}$ at $175 \mathrm{~A}$ by cooling the current leads by evaporating He gas.

\section{F. Stray Magnetic Field and Electro-magnetic Shield}

Because of restriction on layout space, many valves and instruments must be set near the magnet. There was a concern that stray magnetic field may affect the performance of the valve control, the measuring system and so on.

The stray magnetic field analysis was carried out with $7 \mathrm{~T}$ excitation of the magnet. It is more than 25 Gauss within $3 \mathrm{~m}$ from the center of the magnet. As a result, some of the control valves and measuring instruments would be affected by the field as it was. In order to reduce the stray field at the key components less than 20 Gauss, the electro-magnetic shielding panels and boxes made of iron were equipped for control valves, weight scale, control panels based on the analytical results.

\section{G. Measurement, Control and Interlock Systems}

All the control valves, the excitation control and the measuring system were remote-operated through optical fiber connected computer controls. The control and measurement site is $71 \mathrm{~m}$ away from the facility site.

Excitation powers delivered to one of test samples and the superconducting magnet are given by the remote-controlled power supplies set next room to the main facility room.

At the event of emergency or accessing the experimental setup, the interlock system immediately shutdown all the heating power and open the vent valves for safety. As for the superconducting magnet, the stored energy will be discharged to the power supply at the maximum rate. The events of emergency are as follows; $1: \mathrm{LH}_{2}$ cryostat pressure exceeds 2.0 MPa, 2: $\mathrm{GH}_{2}$ feed line pressure exceeds $2.0 \mathrm{MPa}, 3: \mathrm{GN}_{2}$ pressure of the blanket for current leads exceeds $0.15 \mathrm{MPa}$ and falls below $0.105 \mathrm{MPa}$.

\section{Functional Tests}

\section{A. Insert for $\mathrm{LH}_{2}$ Cryostat and Test Section}

Test section is inner-bottom area (309 mm diameter and 400 mm height) of the $\mathrm{LH}_{2}$ cryostat where the external magnetic field is generated by the superconducting magnet immersed in LHe (see Fig. 2). Fig. 3 shows the photo view of the insert for the $\mathrm{LH}_{2}$ cryostat. The upside area of the bottom FRP flange, we have set a test sample, that is, small test coil wound by Bi2223 wire (Sumitomo DI-BSCCO wire Type ACT).

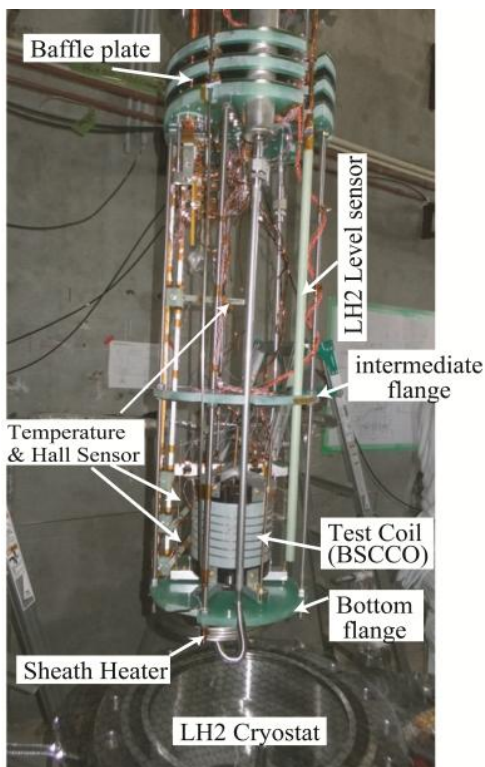

Fig. 3. Photo view of the insert for the $\mathrm{LH}_{2}$ cryostat and test samples set in the test section.

\section{B. Cooling Test}

At first, the LHe cryostat was pre-cooled by liquid nitrogen.

Secondly, liquid hydrogen was transferred from $\mathrm{LH}_{2}$ container $(2000 \mathrm{~L})$ through flexible transfer tube. Temperature change inside the $\mathrm{LH}_{2}$ cryostat was measured by Cernox sensors (T5, T6 and T7; see Fig.2) as shown in Fig. 4 (left). At the time of $2 \mathrm{~min}$., $\mathrm{LH}_{2}$ transfer started, however, due to small trouble, the operation was suspended for about $8 \mathrm{~min}$. The transfer operation re-started at $11 \mathrm{~min}$. The temperature sensor T7 (set at $50 \mathrm{~L} \mathrm{level)} \mathrm{touched} \mathrm{liquid} \mathrm{hydrogen} \mathrm{at} \mathrm{about} 22 \mathrm{~min}$. It took about $11 \mathrm{~min}$ to fill up the main cryostat. Temperature change during $\mathrm{LH}_{2}$ re-filling is shown in Fig.4 (right) together with $\mathrm{LH}_{2}$ level measured by the level meter using $\mathrm{MgB}_{2}$ wire.

Then the liquid nitrogen in the outer (LHe) cryostat was purged out. LHe cryostat was filled with helium gas. Next, the liquid helium was transferred to the outer cryostat from LHe container. Temperature trends measured by Cernox sensors are shown in Fig.5. Setting location of the Cernox temperature sensors $(\mathrm{T} 1 \sim \mathrm{T} 4)$ was shown in Fig. 2. Liquid helium was filled up within one hour. 

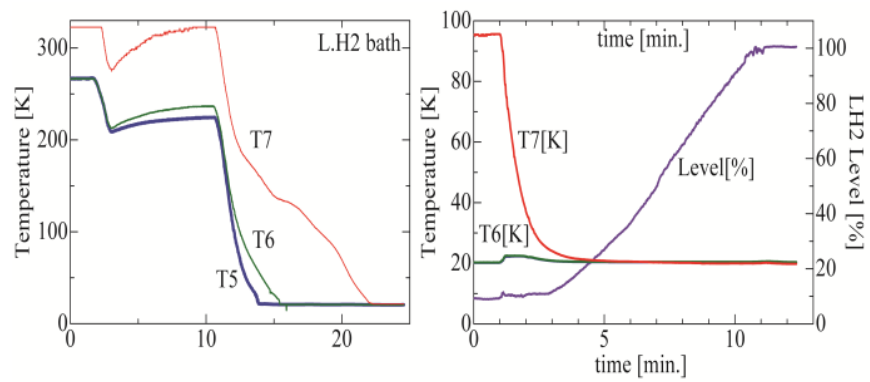

Fig. 4. Cooling down characteristics of $\mathrm{LH}_{2}$ cryostat (left) and re-filling $\mathrm{LH}_{2}$ (right).

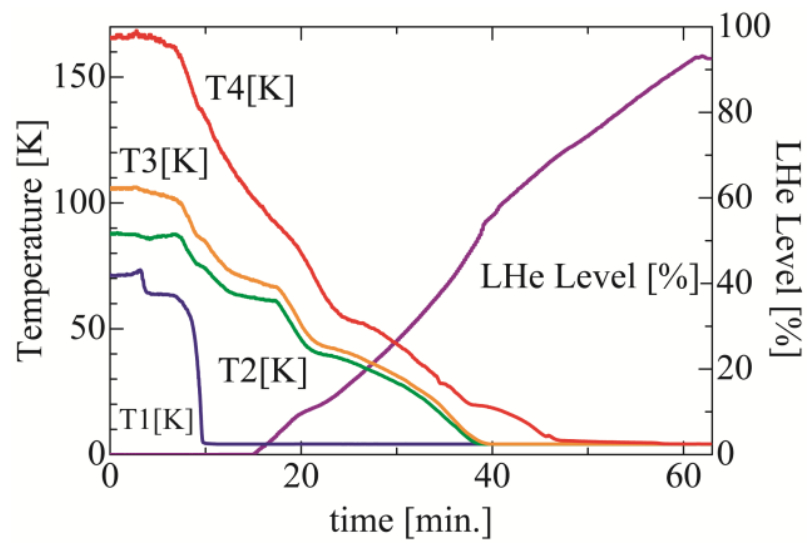

Fig. 5. Cooling down characteristics of LHe cryostat.

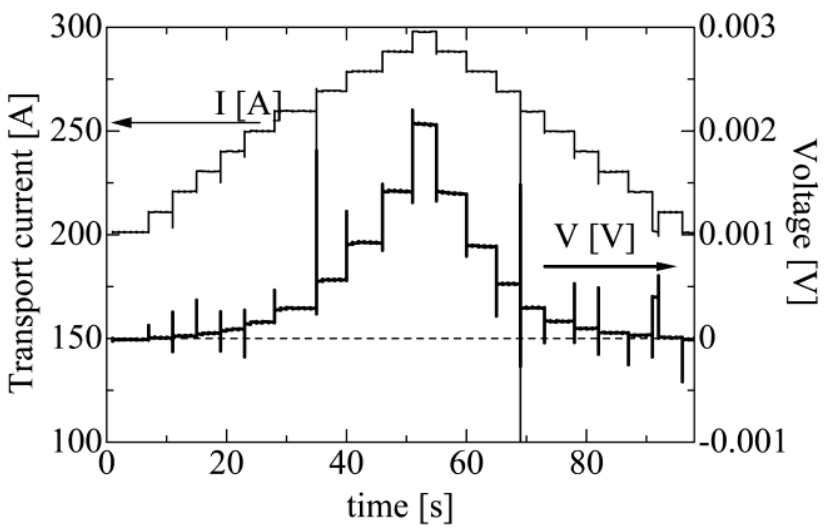

Fig. 6. Current through the Bi2223 small coil and tap voltage of the coil near the critical current.

\section{Superconductor Excitation Test}

The test Bi2223 small coil was energized by the remotecontrolled power supply up to its critical current as shown in Fig. 6. The sample coil was excited up to $300 \mathrm{~A}$ with $10 \mathrm{~A}$ step by the current source. The coil tap voltage appeared above $200 \mathrm{~A}$ of transfer current. The current was successfully introduced to the sample set in the $\mathrm{LH}_{2}$ cryostat.

\section{Magnetic Field at Test Section}

The superconducting magnet excitation test was carried out. The voltage range of the power source was $-10 \sim 10 \mathrm{~V}$. As the magnet inductance is $112.36 \mathrm{H}$, the current increasing or decreasing rate is less than $0.089 \mathrm{~A} / \mathrm{s}$. Moreover, there is voltage drop along the power lead cables to the magnet, therefore the rate becomes smaller.

Fig. 7 shows one of the sample result of the magnetic field (Hall sensor H1: see Fig.2) change test. The magnet current was ramped up to $50 \mathrm{~A}(2.1 \mathrm{~T})$ and kept for $20 \mathrm{~min}$. Then it was ramped up again to $100 \mathrm{~A}$ ( $4.2 \mathrm{~T}$ ), and after $20 \mathrm{~min}$., the magnet was discharged once. The magnet was charged again up to $150 \mathrm{~A}(6.3 \mathrm{~T})$ and then discharged.

During the whole test, the LHe level was also plotted on the same figure. At the beginning of the charging, LHe was almost filled up full. LHe level was decreased to $55 \%$ (level at the top flange of the magnet) with about 5 hours operation.

The stray field distribution around the cryostat was measured at every magnet current (50,100 and $150 \mathrm{~A})$. The stray field near the valves and measuring instruments was sufficiently reduced by the shielding panels and boxes. There was no degradation in performances of the valves and measuring instruments.

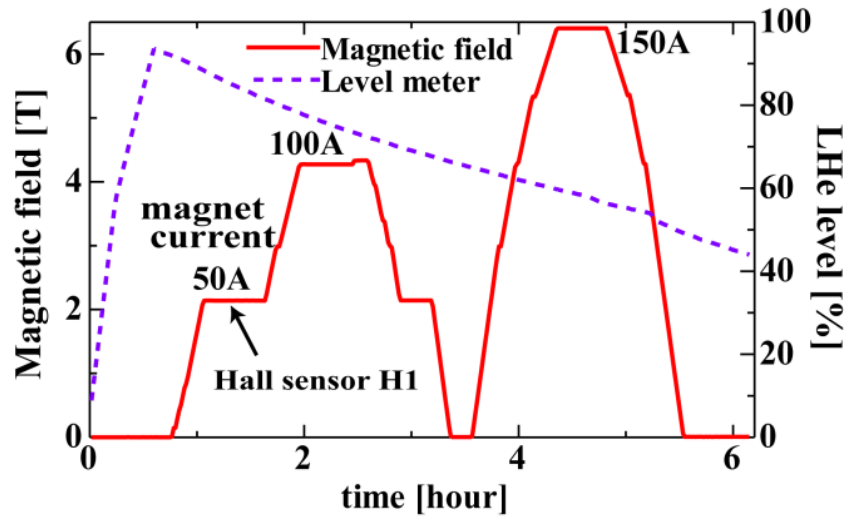

Fig. 7. Magnet excitation pattern and trend of LHe level.

\section{CONCLUSION}

In order to clear the cooling properties of the $\mathrm{LH}_{2}$, we have developed the thermal-hydraulics experimental system for wide ranges of subcoolings, pressures up to supercritical and flow velocities in forced flow cooling.

In addition, the new experimental set-up to evaluate the electro-magnetic properties of superconductors cooled by liquid hydrogen was designed and fabricated.

The cryostat of $\mathrm{LH}_{2}$ of $309 \mathrm{~mm}$ inner diameter was set coaxially with vacuum layer in the LHe cryostat in which the LHe cooled superconducting magnet for external magnetic field (up to $7 \mathrm{~T}$ ) was set. The $\mathrm{LH}_{2}$ cryostat has three power leads for feeding up to $500 \mathrm{~A}$ to the test high-Tc superconductors.

The fundamental functional test results of cooling test, basic operation test were successfully performed. Remote control systems and interlock systems were also designed to carry out the experiment safely.

\section{ACKNOWLEDGMENT}

The authors thank technical staffs of JAXA for assisting in the experiments. This research was supported in part by JSTALCA, Japan. 


\section{REFERENCES}

[1] Steward, W. G., "Onset of Nucleate and Film Boiling Resulting from Transient Heat Transfer to Liquid Hydrogen," in Advances in Cryogenic Engineering 35, Plenum, New York, 1990, pp. 403-412.

[2] Graham, R. W., Hendricks, R.C., and Ehlers, R.C., "An Experimental Study of the Pool Heating of Liquid Hydrogen in the Subcritical and Supercritical Pressure Regimes over a Range of Accelerations," in Advances in Cryogenic Engineering 10, Plenum Press, New York, 1965, pp. 342-352.

[3] Class, C. R., Dehaan, J. R., Piccone, M., and Cost, R. B., "Boiling Heat Transfer to Liquid Hydrogen from Flat Surfaces," in Advances in Cryogenic Engineering 5, Plenum, New York, 1960, pp. 254-261.

[4] Shirai Y., Tatsumoto H., Hata K., Shiotsu M., Kobayashi H., Naruo Y., Inatani Y., Preliminary Study on Heat Transfer Characteristics of Liquid Hydrogen for Coolant of HTC Superconductors", in Advances in Cryogenic Engineering 55A, AIP, New York, 2010, pp.337-344.

[5] Shirai, Y., Tatsumoto, H., Shiotsu, M., Hata, K., Kobayashi, H., Naruo, Y. and Inatani, Y., "Boiling heat transfer from a horizontal flat plate in a pool of liquid hydrogen ", Cryogenics, 50, pp.410-416 (2010).

[6] Yasuyuki Shirai, Hideki Tatsumoto, Masahiro Shiotsu, Koichi Hata, Hiroaki Kobayashi Yoshihiro Naruo, Yoshifumi Inatani, Katsuhiro Kinoshita, "Forced flow boiling heat transfer of liquid hydrogen for superconductor cooling", Cryogenics Vol..51(2011) 295-299 